\title{
Ferroelectric Liquid Crystals from Bent-Core Molecules with Vinyl End Groups
}

\author{
Soon-Sik Kwon, Tae-Sung Kim, Chong-Kwang Lee, 'Sung-Tae Shin,' \\ Lee-Tack Oh, ${ }^{+}$E-Joon Choi, $+\underset{+}{+}$ Sea-Yun Kim, \\ Dept. of ('hemistry, Gieongsang Aational Thiversit, Jinu 660-701, Korea \\ ${ }^{\dagger}$ Dept of Phisics, Korea Thiversit?, Chmgnam 339-700, Korea

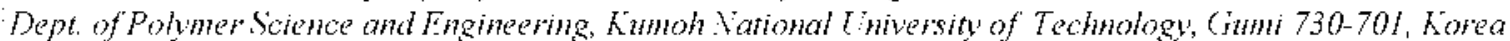

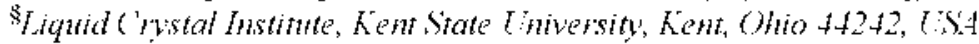 \\ Received May 20,2002
}

\begin{abstract}
New banana-shaped achiral compounds. 1,3-pheny lene bis $[4-\{4$-(alkeny losy ) pheny liminomethy 1 ; thenzoate $]$ s were synthesized by varying the length of alkenyl group: their ferroelectric properties are described. The snectic mesophases. including a switchable chiral smectic $\left(C^{\prime}\left(\sin C^{*}\right)\right.$ phase, were characterized by differential scanning calorinetry, polarizing optical microscopy and triangular wave method. The presence of vinyl groups at the terminals of linear side wings in the banana-shaped achiral molecules containing schitf s base mesogen induced a decrease in melting temperature and formation of the switchable sin $C^{*}$ phase in the melt. "The smectic phases having the octeny lowy group such as $\left(\mathrm{ClI}_{2}\right)_{6} \mathrm{Cll}=\mathrm{Cll}$ showed ferroelctric switching, and their values of spontaneous polarization on reversal of an applied electric field were $120 \mathrm{nC} / \mathrm{cm}^{2}(\mathrm{X}=\mathrm{ll})$ and $225 \mathrm{nC} /$ $\mathrm{cm}^{2}(\mathrm{X}=\mathrm{F})$. respectively. We could obtain ferroelectric phases by controlling the number of carbon atom in alkent loxy chain of a bent-core molecule.
\end{abstract}

Key Words : Banana-shaped liçuid erystal, Switehable smectic C, Spontancous polarization, Ferroclectric properties, Bent-core molecule

\section{Introduction}

A mesogenic compound of non-linear molecular structure was discovered for the first time by Volander.' Most chiralities of liquid crystal phases are due to the introduction of a chiral group containing chiral carbon. The chiral phase can also occur without chiral structure by spontaneous polarization derived from symmetry breaking. ${ }^{-i-5}$ A fascinating example of the achiral symmetry breaking was found in the tilted smectic plases of banana-shaped molecules Because of the director tilt and the simultaneous polar ordering. each smectic layer loses its inversion symmetry and becomes chiral. although the molecules contain no chiral carbons. Recently. ferroelectric liquid crystal phases formed from achiral molecules have been reported in which smectic phases of banana-shaped molecules could show ferroelectric switching. ${ }^{\text {(x) }}{ }^{1 i)}$ The existence of such a mesophase depends upon the length of the rigid core and the number of carbon atom in linear side wings as well as the magnitude of bent and its position. Since the bent-core molecules are closely packed and are all aligned in the direction of bending. they form a unique smectic phase."

Niori et al. reported the first obvious example of ferroelectricity in banana-shaped achiral molecules. ascribing the polar packing of the molecules with $\mathrm{C}_{2 y}$ symmetry: Link et $a l^{6}$ reported the first spontaneous formation of chirality in a smectic phase of banana-shaped achiral molecules. a chiral layer stnicture with a handedness

"Corresponding Author. Fax: +82-55-761-0244: L-mail: cklec' $a$ ' nongae.gsnu.ac.kr

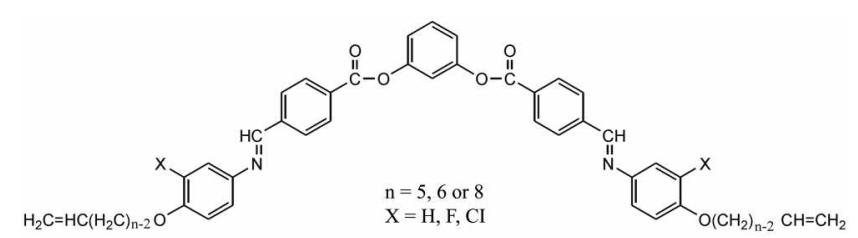

1,3-phenylene bis [4-\{4-(alkenyloxy)phenyliminomethyl $\}$ benzoate]

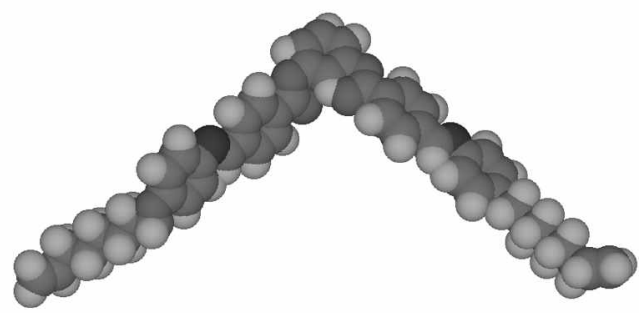

Skeleton of the compound with $\mathrm{n}=8$ and $\mathrm{X}=\mathrm{H}$

depending on the tilted molecular direction. Weissflog et $a l^{12}$ reported that ferroelectricity could be detected for one of the mesophases in some achiral banana-shaped molecules by varying direction of comecting groups and substituents. Currently, ferroelecric liquid crestals that exhibit spontaneous polarization due to their self-organizing character are regarded as one of the most promising groups of optoelectronic materials. ${ }^{13.14}$

In this study: new banana-shaped achiral molecules having vinyl end groups were synthesized. and their ferroelectric liquid crystalline properties were irvestigated to determine the relationship between the liquid crystallinity and structural changing of the vinyl groups. We could obtain ferroelectric phases by controlling the number of carbon atom in alkenyl- 


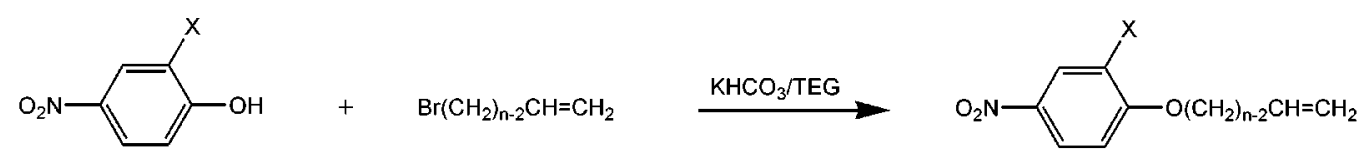

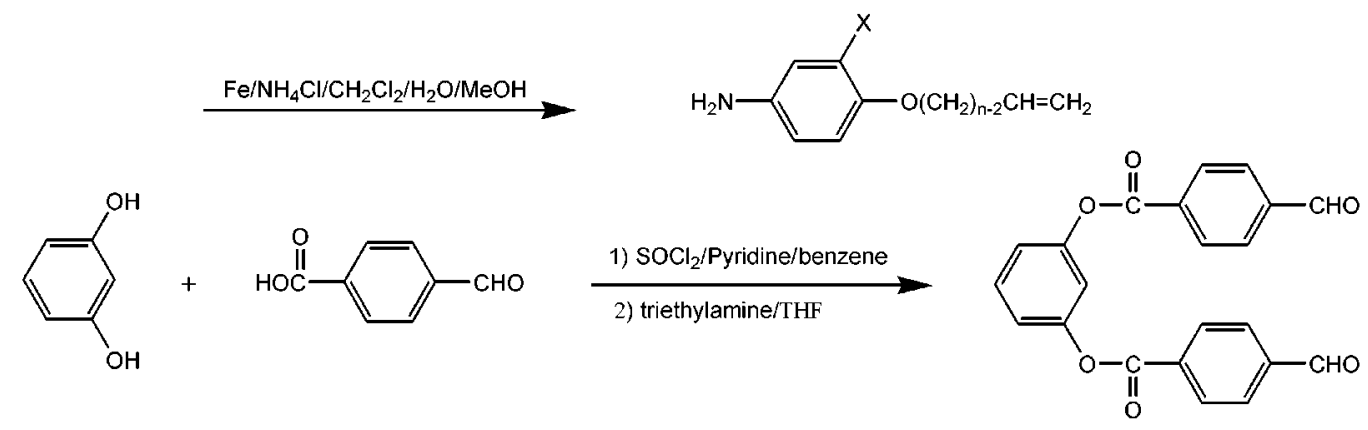

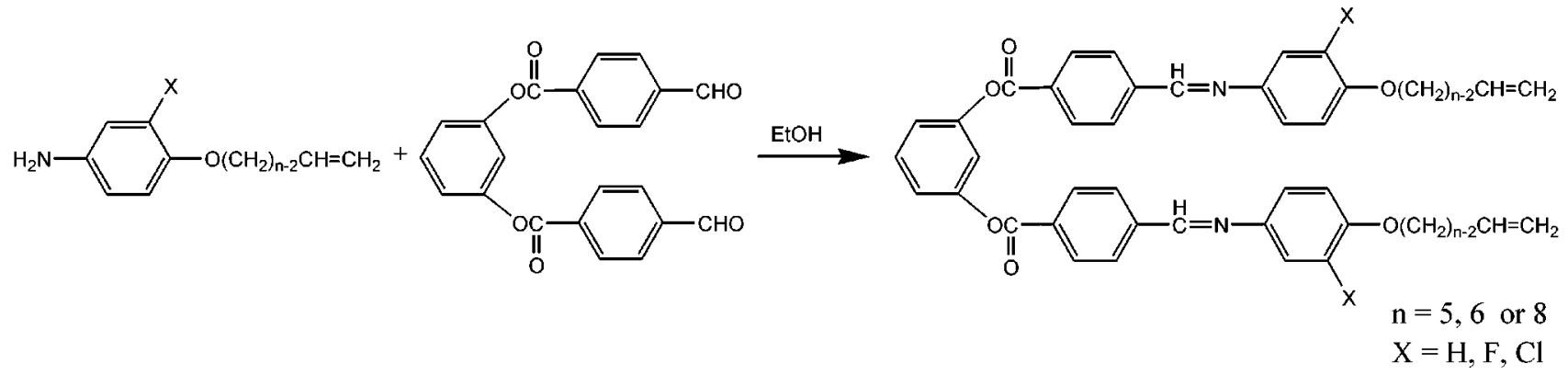

Scheme 1

oxy chain and introducing the lateral substituent in the 3position of Scliff's base moiety of a bent-core molecule.

\section{Experimental Section}

The syntheses of 1.3-phenylene bis [4-\{t-(4-pentemyloxy)pheny liminomethyl;benzoate] (PBPEB), l.3-phenylene bis [4-\{4-(5-hexeny loxy )-(PBHEB). 3-fluoro-5-hexeny loxy (PBFHEB). 3-chloro-5-hexeny loxy-(PBCHEB). 7-octemy loxy(PBOEB). 3-fluoro-7-octeny loxy -(PBFOEB) and 3-chloro7-octenyloxy-(PBCOEB)-phenyliminomethyl; benzoate] were achieved by a general sy nthetic method ${ }^{1516}$ as shown in Scheme 1. First. 4-nitro-1-alkenyloxybenzene was prepared by substitution reaction of 4-nitrophenol and bromoalkene. Then. +-alken loxyaniline (I) was obtained by hydrogenation of 4-nitro-1-alkenyloxybenzene with iron in the presence of $\mathrm{CH}_{\beth} \mathrm{Cl} \sqrt{ } / \mathrm{MeOH} / \mathrm{H}_{2} \mathrm{O}$ solvent mixture. Next, 1,3-phemy lene bis(4-formyl benzoate) (ll) was prepared by reaction of resorcinol and 4-formyl benzoyl chloride in tetrahydrofuran with triethylamine at 0 " $\mathrm{C}$. Finally the product was prepared by condensation reaction between the aniline (I) and the dialdehyde (ll). The final product was purified by chromatography on silica gel, and recrystallized several times from a mixture of ethanol and dimethylformamide $(20: 1$. v/v). Yield after purification was $20-30 \%$. The representative spectroscopic data obtained by means of NMR and Mass spectroscopy: 'H NMR (CDCl $\left.\mathrm{C}_{\text {. }} 500 \mathrm{MHz}\right)$ for PBOEB: $\delta=1.3-1.5$ [m. 12H. $\left.-\left(\mathrm{CH}_{2}\right)_{3}-\right] .1 .8\left(\mathrm{~m},+\mathrm{H} .-0 \mathrm{CH}_{-} \mathrm{CH}_{-}-\right) .2 .0$ (m. $\left.+\mathrm{H} .-\mathrm{CH}_{2} \mathrm{CH}=\right)+.0\left(\mathrm{t}, 4 \mathrm{H},-\left(\mathrm{CH}_{2}\right) .5 .0\left(\mathrm{q} .+\mathrm{H} .=\mathrm{CH}_{2}\right)\right.$, 5.8 (m. 2H. $-\mathrm{CH}=$ ) $6.9-8.3$ (m. $20 \mathrm{H}, \mathrm{Ar}-\mathrm{H}) .8 .5$ (s, $2 \mathrm{H}$,
- $\mathrm{CH}=\mathrm{N}-$ ); EIMS $m z 776$ (M). HRMS (EI) calcd for $\mathrm{C}_{50} \mathrm{H}_{52} \mathrm{~N}_{2} \mathrm{O}_{6}(\mathrm{M}): 776.3825$. Found: 776.3827 . The remaining banana-shaped compounds were prepared and confirmed by the same method with PBOEB.

NMR spectra were obtained by Brucker DRX NMR spectrometer. Mass spectra were measured on a JEOL JMS700 spectrometer. The transition behaviors were characterized by differential scamuing calorimetry (Perkin-Elmer DSC7) and by polarizing microscopy (Nikon Eclipse E400 POL). DSC ineasurements were performed in $\mathrm{N}_{2}$ atmosphere with heating and cooling rate of $5^{\circ} \mathrm{C} / \mathrm{mun}$. Optical texture observation was carried out using a polarizing microscope with a hot plate. The switching current was examined by the triangular wave method. ${ }^{1 ?}$ The sample cell was mounted in a microfurmace for measuring the spontaneous polarization with varying temperature. The temperature fluctuations inherent to the furnace were approximately $0.1^{\circ} \mathrm{C}$. For direct measurement of the polarization, we used the triangular wave method for ease of subtracting the background current. The polarization current. converted into voltage signal through an amplifier. was measured in a digitizing oscilloscope and fed into a computer for data analyses.

\section{Results and Discussion}

Synthesis and mesogenic behasiors. The synthetic route for the banana-shaped compound is rather straightfonward and each reaction step is relatively well-known. The obtained compounds were characterized by means of NMR and Mass spectroscopy. NMR and Mass spectral data were in accor- 
Table 1. Phase transition temperatures on cooling and the number of carbon atom in the alkenyloxy chans (n)

\begin{tabular}{|c|c|c|}
\hline Number of Carbon Atom (n) & Transition Temperature "C (Inthalpy $\mathrm{J}_{\mathrm{mol}}{ }^{-1}$ ) & Suitching Property \\
\hline $5(\mathrm{X}-\mathrm{H})$ & $\operatorname{Cr} 107.0(47.1) \mathrm{I}$ & Notie \\
\hline $6(X-11)$ & Cr $146.8(18.5) \mathrm{SmX}_{1} 157.2(10.9) \mathrm{SmX}_{2} 160.9(8.1)$ I & None \\
\hline $6(X-1)$ & $\mathrm{Cr} 45.5(5.8) \mathrm{SmX}_{1} 115.7(35.7) \mathrm{SmX}_{2} 1.38 .4(10.1) 1$ & None \\
\hline $6(X-C)$ & C.r $103.7(9.0) \mathrm{l}$ & None \\
\hline $8(X-11)$ & Cr $130.8(27.2) \mathrm{SmX}_{1} 142.9(17.1) \mathrm{SmC}^{-} 159.8(25.4)$ & Switchable \\
\hline $\left.8(X-1)^{\prime}\right)$ & $\operatorname{Cr} 105+4(26.6) \operatorname{Smc} 139.2(7.9) 1$ & Switehable \\
\hline $8(X-C ! 1)$ & $(\mathrm{C} \log 8)(1+10) \mathrm{I}$ & None \\
\hline
\end{tabular}

dance with expected formulae. The relationship of the transition temperatıre and the number of carbon atom in the alkeny loxy chains (n) at the linear terminal side wings are shown in Table 1 . In the table. among the seven banamashaped molecules synthesized. molecules $(X=H$, and $F)$ of alkenyl group with $n=8$ were switchable in their liquid crystal plases. Comparing these molecules with $n=8$ to the molecules with $n=5$, the alkenyl group length could be reasoned to be too short to form mesophase. The molecules of the alkenyl group with $n=6$ were not switchable in their mesoplases but could form smectic phase. Banama-shaped molecules with electron withdrawing groups are expected to decrease the intralamellar electrostatic repulsion in the direction of their longitudinal dipoles and thus the molecules consisted of substituents with positive Hammett Substituent Constant $(\sigma)^{18}$ value could exhibit smectic phases. In the literature the introduction of a central substituent in the 1,3pheny lene moiety is reported to decrease the smectic thermal stability ${ }^{\mid 9,-17}$ in the present study the presence of a lateral clulorine substituent at 3-position of the Schiff's base moiety prevents the regular stacking of the molecules so that they could not form mesophase. Figure l(a) shows DSC thermogram of PBOEB with $n=8$. In the heating DSC thermogram. three endothermic peaks were appeared: the first one for the melting at $148.8^{\circ} \mathrm{C}$. the second one for smectic $\mathrm{X}_{1}\left(\operatorname{Sm} \mathrm{X}_{1}\right)$ to- $\mathrm{Sm} \mathrm{C} \mathrm{C}^{*}$ phase at $157.3^{\circ} \mathrm{C}$, and the third one for the clearing at $162.3^{\circ} \mathrm{C}$. In the cooling $\mathrm{DSC}$ thermogram. three exothermic peaks were obsened: the first one for isotropic liquid-to-Sm $\mathrm{C}^{*}$ phase at $159.9^{\circ} \mathrm{C}$. the second one for $\mathrm{Sm}$ $\mathrm{C}^{*}$-to-SmX at $1+3.0^{\circ} \mathrm{C}$. and the third one for cry stallization at $130.8^{\circ} \mathrm{C}$. Figure $\mathrm{l}(\mathrm{b})$ shows DSC themograms of PBFOEB with $n=8$. In the heating DSC thermogram. three endothermic peaks were appeared: the first one for the melting at 71.4 " $\mathrm{C}$. the second one for smectic $\mathrm{X}_{1}\left(\mathrm{SmX}_{1}\right)$-to-Sm $\mathrm{C}^{*}$ phase at $114.7^{\circ} \mathrm{C}$, and the third one for the clearing at 139.2 "C. In the cooling DSC thermogram. two exothermic peaks were observed: the first one for isotropic liquid-to-Sm $\mathrm{C}^{*}$ phase at $139.18{ }^{\circ} \mathrm{C}$, the second one for cristallization at about $105.4^{\circ} \mathrm{C}$.

Micmoscopy texture. Using an optical microscope with crossed polarizer. on cooling the isotropic liquid samples we could identify even phase transitions shown in Table 1. As shown in Figure 2. when the isotropic liquid of PBOEB with $\mathrm{n}=8$ and $\mathrm{X}=\mathrm{H}$ is cooled slowly. optical texture of smectic phase appears as a striped gramual pattern at the isotropic-toSn $C^{*}$ phase transition temperathire. The texture tends to
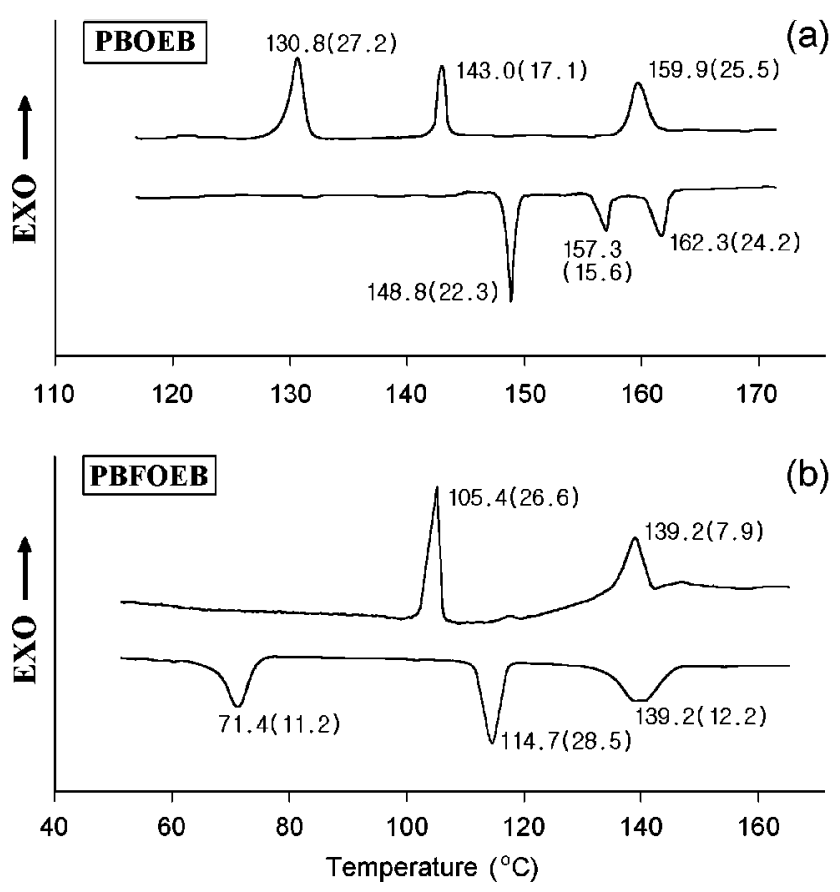

Figure 1. (a) DSC themogram of healing and cooling of PBOEB with $n=8$. (b) DSC themogram of heating and cooling of PBIOOEB with $11=8$.

transform into mesomorphic domain. At about $134^{\circ} \mathrm{C}$. smectic phase is changed abruptly to paramorphic texture that grows to become mosaic texture with schlieren remmants to room temperature. Figure 3 shows optical texture of PBFOEB with $n=8$ and $X=F$. On cooling, optical texture of smectic phase of PBFOB appears as very small granual pattem at the isotropic-to-Sm $\mathrm{C}^{*}$ phase transition temperature. The texture tends to transform into mosaic texture with small domains gradually: As it was further cooled. smectic phase is changed abniptly at $103.5^{\circ} \mathrm{C}$. Then, the texture grows to become schlieren texture of the twisted smectic state to room temperature.

Spontaneous polarization and switching current. In order to characterize the smectic phase, we measured spontaneous polarization of the sample. For the measurement. a cell is made up of conductive indium-tin-oxide coated glasses. treated with rubbed polyimide for the aligiment. The cell gap was maintained by patterned organic spacer of $1.5 \mu \mathrm{m}$ thickness. The spontaneous polarization was measured by applying triangular shape voltage, and the switching was also observed by using a polarized microscope. Figure 4 


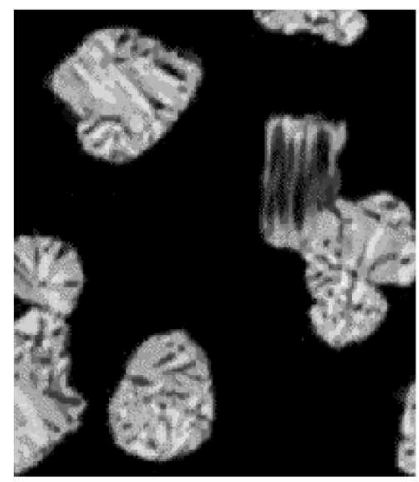

(a)

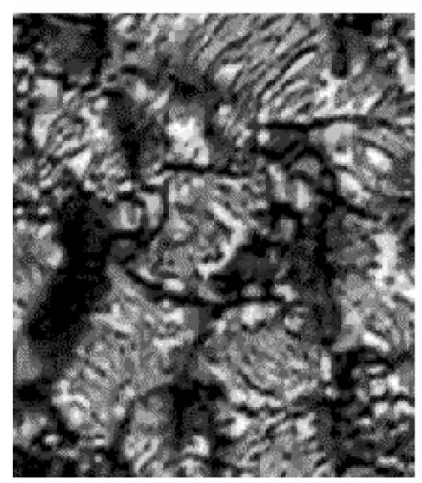

(c)

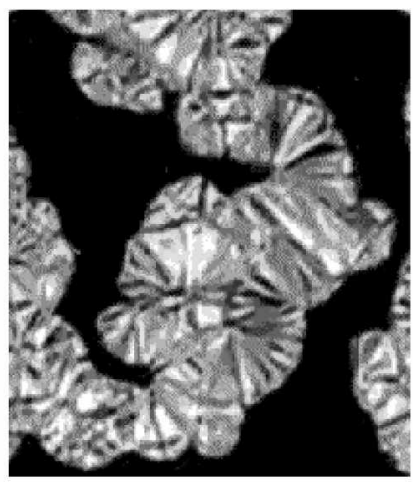

(b)

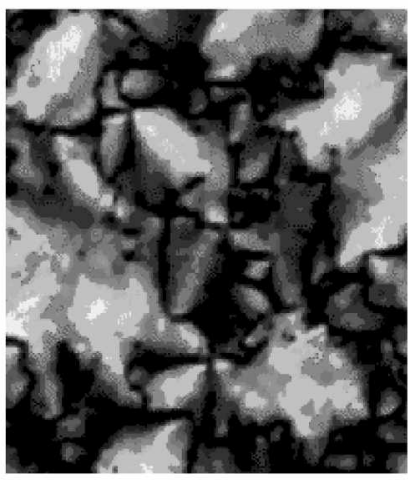

(d)

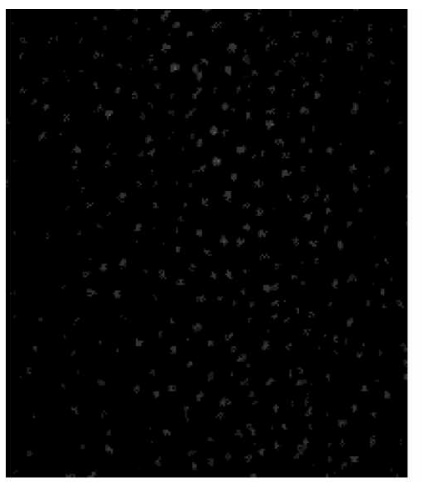

(a)

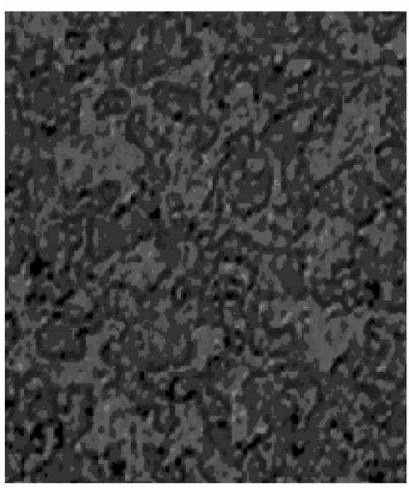

(c)

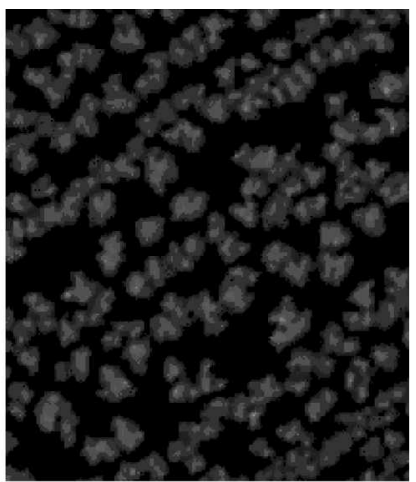

(b)

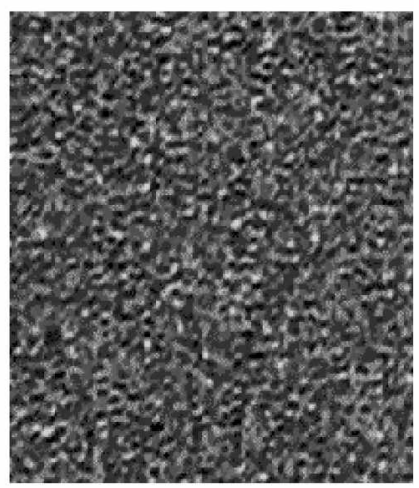

(d) $\overline{30 \mu \mathrm{m}}$

Figure 2. Optical micrographs of $\operatorname{Sin} \mathrm{C}^{*}$ phase for PBOF.B with n= $=8$ on cooling trom the isotropic liquid. (a) Sm $C^{*}$ phase appears as a striped granual pattem at the isotropic-to-sm $C^{*}$ phase transition temperalure. (b) the lexture kends to transtom into mesomorphic domain. (c) $\Lambda$ s it was futher cooled the smectic phase is changed abruptly to paramoryhic texture at 1.34 " $\mathrm{C}$. (d) then, the lesture grows to become mosaic lesture with sechlieren remuants to room lemperaturs.

shows the polarization reversal current for PBOEB and PBFOEB with $n=8$ at the temperature corresponding to two smectic phases. $\mathrm{SmX}_{1}$ and $\mathrm{Sm} \mathrm{C}^{*}$. In Figure $+(\mathrm{a})$, the one

Figure 3. Optical micrographs of $\mathrm{Sm} \mathrm{C}^{*}$ of PBFOF.B with $\mathrm{n}=8$ on cooling from the isotropic licuict. (a) Sm $C^{*}$ phase appears as very small granual patem at the isolropic-to-Sm $C^{*}$ phase transition temperature. (b) The texture grows to become granual pattern. (c) lhe texture tends to transtom into mosaic texture with small domains gradually (d) As it was further cooled, smectic $C$ phase is changed abruptly at 103.5 "C. Then, the texture grows to become schlieren texture of the twisted smectic state to room temperature.

sharp peak of reversal current for every half period was observed at $146^{\circ} \mathrm{C}$ (temperature within Sin $\mathrm{C}^{*}$ phase forming region) and the broad pattern at $136^{\circ} \mathrm{C}$ (temperature within
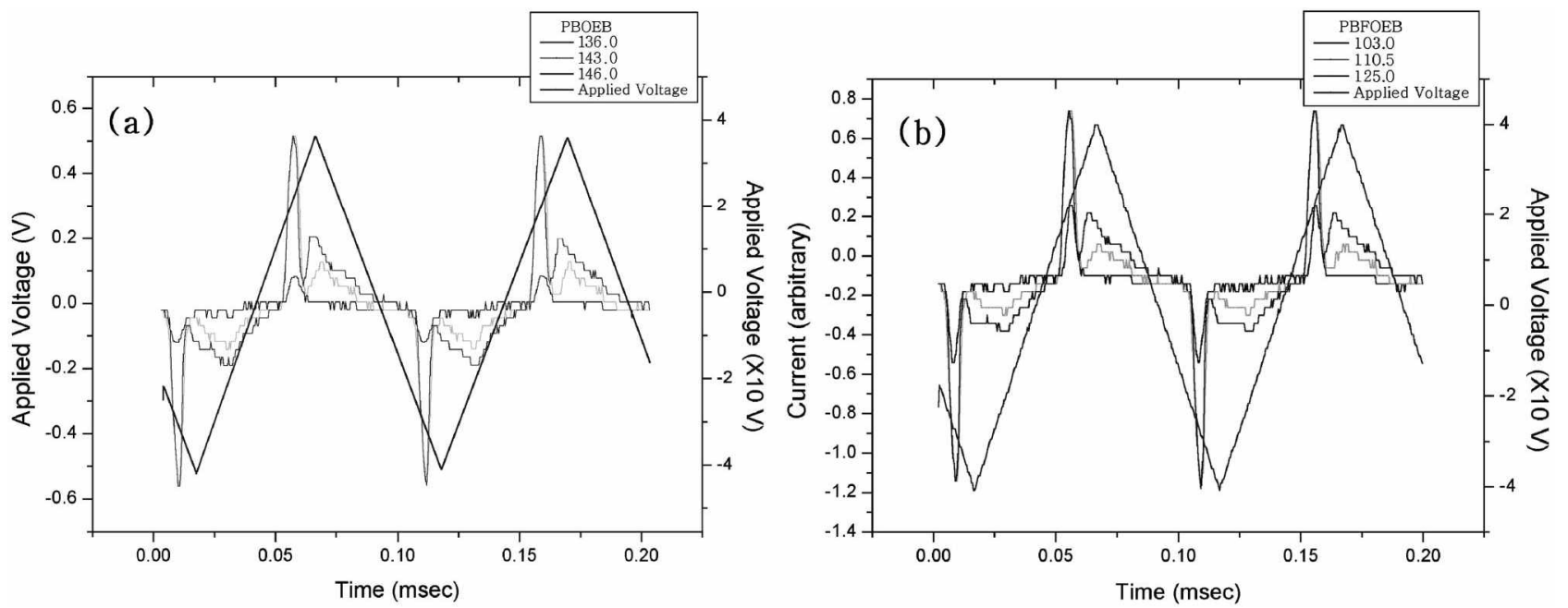

Figure 4. (a) The switching current curve obtained by applying a triangular volage wave lor PBOLB with $n=8$. (b) The stitching current curve oblaind by applying a triangular voltage wave for $\mathrm{PBFOLB}$ with $\mathrm{nl}=8$. 

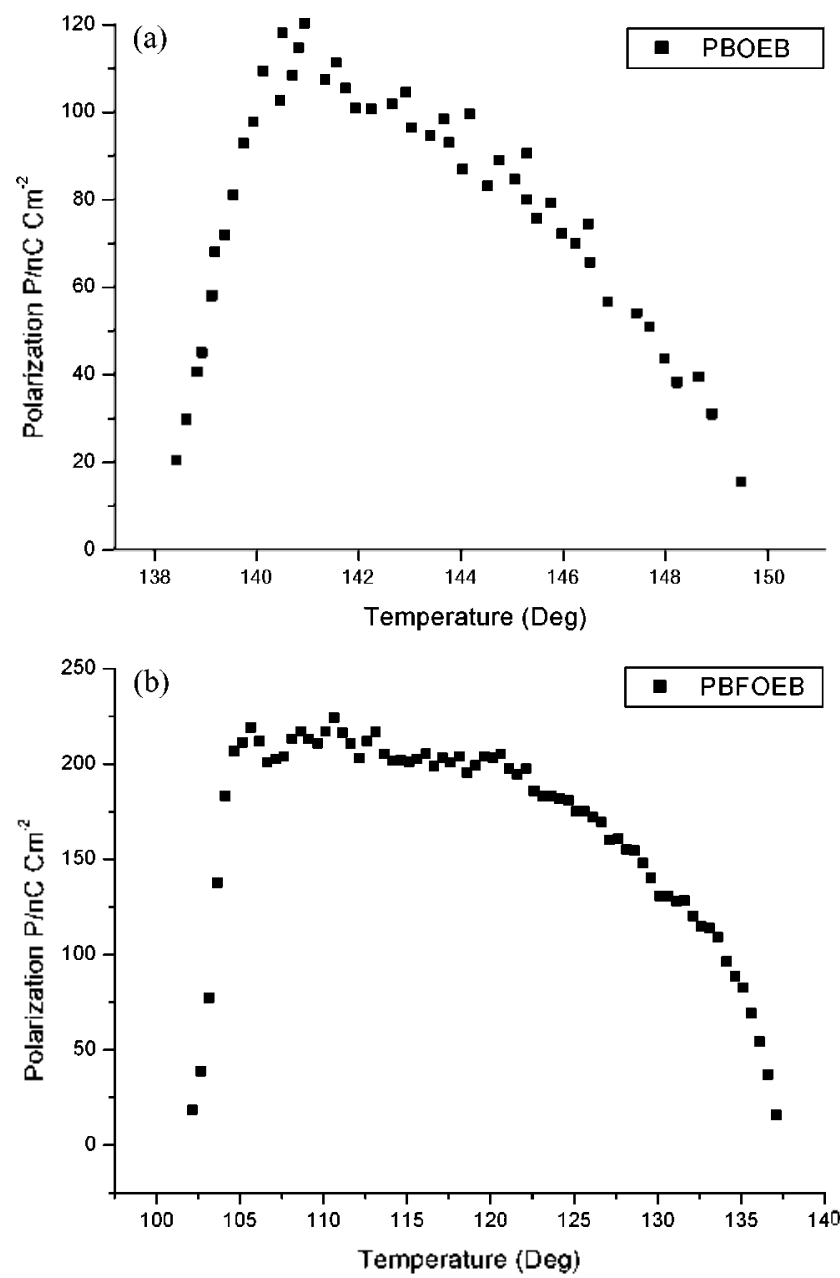

Figure 5. (a) The temperature dependence of spontaneous polatization for $\mathrm{PBOFB}$ with $n=8$. The temperature dependence of sponlancous polarization for PlBliOLiB wilh $n=8$.

$\mathrm{SmX}_{1}$ forming region). In Figure +(b). the one sharp peak of reversal current for for every half period was observed at 125 ${ }^{\circ} \mathrm{C}$ (temperature within $\mathrm{Sm} \mathrm{C}^{*}$ phase forming region) and the broad pattern at $103^{\circ} \mathrm{C}$ (temperature within $\mathrm{SmX}$ forming region). Thus. we can conclude that the $S m C^{*}$ phase of the compounds (PBOEB and PBFOEB) is ferroelectric with the tip of the bent molecule orienting along the electric field and reversing its orientation on the polarity of the field. Figure 5 shows temperature dependence of spontaneous polarization for PBOEB and PBFOEB in the cooling experiment. In Figure 5(a). the switchable smectic phase exhibits a maximum polarization of about $120 \mathrm{nC} / \mathrm{cm}^{2}$ for PBOEB. In Figure 5 (b), the smectic phase exhibits a maximum polarization of aboput $225 \mathrm{nC} / \mathrm{cm}^{2}$ for PBFOEB. On cooling the isotropic liquid. the spontaneous polarizations are increased with decreasing temperature. The spontaneous polarization dramatically decreased with lowering temperature below each critical temperature. The sharp decrease of polarization suggested that the smectic phase-to-solid phase transition is the first order. On further lowering the temperature, the polarization was vanished. because of crystallization of the central rod parts of the molecules.

\section{Conclusions}

The introduction of a lateral substituent (halogen atom) in the 3-position of a Scluff's base moiety reduced the transition temperature and the degree of crystallinity of the switchable banana liquid crystal. Also. the introduction of vinyl groups onto the terminals of bent-core molecules containing Schiff's base mesogen reduced the melting and the clearing temperature. The bent-core molecules with vinyl groups at the terminals could form the switchable smectic phase with octeny 1 group $(\mathrm{n}=8)$ even though the constituent molecules are achiral. We concluded that the smectic phase of the banana-shaped molecule having octenyl group except one with chlorine substituent was a chiral smectic $\mathrm{C}$. Considering the switching current corresponding to the spontaneous polarization and optical microscopic textures, the aligned smectic phase was ferroelectric.

Acknowledgement. This work was supported by grant No. R01-2001-00433 from the Korea Science \& Engineering Foundation.

\section{References}

1. Vorländer. D. Ber $1929,63,2831$.

2. Kondepudi, D.: Kauftmann, R. J.: Singh. N. Science 1990, 250, 975 .

3. Lemuan. M.: Seul. M. Phls. Rev Letr. 1992. 69. 2082.

4. P'ang. J.: Clark. N. A. Phus. Rev Letr. 1994. 73. 2332.

5. Qiu. X.: Ruiz-Gracia. J.: Stine. K. J.: Knobler. C. M.: Selinger. I. Phus. Rev Lett. 1991, 67.703

6. I.ink, D. R.: Natale, (j.: Shan, R.: Maclennan. J. F.: Clark. N. A.: Korblova. F.: Walba. D. M. Science 1997. 278, 1924.

7. Niori. T.: Sekine. T.: Watanabe. J.: Furukana T.: Takezoe. H. $J$. Hater Chem 1996. 6(7). 1231.

8. Blinox. L. M. Liq. Cnest 1998. 2f. 143.

9. Toumihac, F.: Blinox: J.. M.: Simon. J.: Yablonsty: S. V. Yatum' $1992,359.621$

10. Sekine, T.: Takanishi, Y.: Niori, T.: Watanabe, J.: Takezoc. U. Ipn. J. Appt. Ifys 1997, 36. L1201.

11. Lee. C. K.: Chien. L. C. Femetectrics 2000. 243. 231.

12. Weissflog. W: Lischka. Cla.: Benne. I.: Schare. T: P'elel. G.: Diele, S.: Kituth. H. In Proce'edings of the Fumpean (onfenewce on hitutid Cinstals, Science and Te'dmologk, 7aopanc: Poland, March 3-8. 1997: pp 126-1.32.

13. Walba. D. M.: Dyer. D. J.: Sierra T.: Cobben. P. L.: Shao. R.: Clark. N. A. J. Am. Chem. Soc. 1999. 118. 1211.

14. Walba. D. M. Scrence 1995. 270. 250.

15. Iassen, A. Alexanian, V. Tetrated dont lett. 1978, 447.

16. I.e., C. K.; Chicm, I. C. Itq. ('r.t. 1999. 26. 609

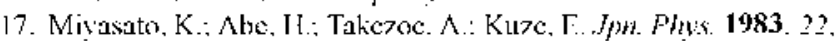
L661.

18. Lee. C. K.: Kwon. S. S.: Chien. L. C.: Choi. E J. Bull Korean Chem. Soc. 2000. 21(1). 1155.

19. Nkutagawa, T.: Matsunaga, Y: Yasulara. A. Iiq. Cakt. 1994, 17 , 659 .

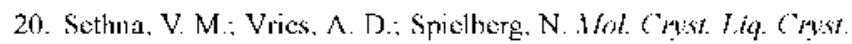
1980. 62. 141 . 